UNIVERSIDADE DE SÃO PAULO

FACULDADE DE ECONOMIA, ADMINISTRAÇÃO E CONTABILIDADE DEPARTAMENTO DE ADMINISTRAÇÃO PROGRAMA DE PÓS-GRADUAÇÃO EM ADMINISTRAÇÃo

PREVISÃO DO CONSUMO DE ENERGIA ELÉTRICA POR SETORES ATRAVÉS DO MODELO SARMAX

Fernando Alves de Moura

Orientadora: Profa. Dra. Alessandra de Ávila Montini 
Prof. Dr. João Grandino Rodas Reitor da Universidade de São Paulo

Prof. Dr. Reinaldo Guerreiro

Diretor da Faculdade de Economia, Administração e Contabilidade

Prof. Dr. Adalberto Américo Fischmann

Chefe do Departamento de Administração

Prof. Dr. Lindolfo Galvão de Albuquerque Coordenador do Programa de Pós-Graduação em Administração 
FERNANDO ALVES DE MOURA

\section{PREVISÃO DO CONSUMO DE ENERGIA ELÉTRICA POR SETORES ATRAVÉS DO MODELO SARMAX}

Dissertação apresentada ao Departamento de Administração da Faculdade de Economia, Administração e Contabilidade da Universidade de São Paulo como requisito para a obtenção do título de Mestre em Administração

Orientadora: Profa. Dra. Alessandra de Ávila Montini

Versão original

SÃO PAULO 
FICHA CATALOGRÁFICA

Elaborada pela Seção de Processamento Técnico do SBD/FEA/USP

Moura, Fernando Alves de

Previsão do consumo de energia elétrica por setores através do modelo SARMAX / Fernando Alves de Moura. -- São Paulo, 2011.

$156 \mathrm{p}$.

Dissertação (Mestrado) - Universidade de São Paulo, 2011.

Orientadora: Alessandra de Ávila Montini.

1. Previsão (Análise de séries temporais) 2. Econometria 3. Energia elétrica 4. Consumo de energia elétrica - Previsão I. Universidade de São Paulo. Faculdade de Economia, Administração e Contabilidade II. Título.

CDD -519.232 